\title{
Classification of air pollution criteria for the improvement of methodical approaches to ensure the environmental safety of major cities
}

\author{
Vadim Bespalov ${ }^{1 *}$, Oksana Gurova ${ }^{1}$, Natalya Samarskaya ${ }^{1}$, and Oksana Paramonova ${ }^{1}$ \\ ${ }^{1}$ Don State Technical University, 344022, 1, Gagarina sq., Rostov-on-Don, Russia
}

\begin{abstract}
The article is devoted to the problem of ensuring environmental safety in the territories of large cities, primarily, to reducing atmospheric air pollution. The aim of the work was to build a comprehensive classification scheme of sources of pollutant emissions into the air basin of the territories of large cities, taking into account the climatic and physicalgeographical conditions of the considered urban areas. In the process of research, we solved the problem of identifying the basic principles of classification of air pollution sources based on the analysis of known methodological approaches with the subsequent improvement of calculation methods to justify the spatial distribution of residential areas, industrial areas, motorways, recreational areas, effective sanitary protective zones taking into account aerodynamics to remove polluted air outside the city territory. A generalized classification of sources of pollutant emissions into the environment is proposed, while the sources of air pollution in urban areas are classified according to the following main criteria: by origin, by aerodynamic parameters and by the nature of the direction of the emission plume, by spatial position and possible mobility, in terms of size in plan, in height of the spread of the emission plume, taking into account the height of the mouth of the source of the emission of pollutants above the level of the earth's surface, in temperature of air-gas mixture, according to the mode of action.
\end{abstract}

\section{Introduction}

In order to ensure environmental safety of the territories of large cities, first of all, attention should be paid to reducing atmospheric air pollution [1]. For this purpose, we systematized the classification features of air pollution sources, while taking into account the geoclimatic conditions of the territories of large cities under consideration. Such a classification scheme of emission sources, based on various classification criteria, will allow us to offer recommendations for improving the well-known methodological approaches to describing the dynamics of the distribution of emissions from various types of atmospheric pollution sources.

Provision of environmental safety of urban areas can be implemented as a result of the following set of measures $[2,3]$ :

\footnotetext{
* Corresponding author: izos-rgsu@mail.ru
} 
1. architectural, planning and organizational, involving spatial separation of the sources of negative impact on the air basin of the considered urban areas and objects of such impact (people, buildings and structures, various purposes, plants, animals, etc.);

2. engineering (technological), involving improvement of technological operations and processes in the sources of negative impact on the air basin, providing minimal or complete elimination of such effects (transfer to other types of fuel, pre-treatment of raw materials, changing technological modes of emission sources operation, etc.);

3. special environmental engineering, involving additional equipment of sources of negative impact on the air basin with engineering tools, equipment, devices, etc., providing a reduction in the level of such exposure to regulatory requirements (sanitary-hygienic and/or environmental).

\section{Theory or experimental methods}

At the first stage of research, we solved the problem of identifying the basic principles of classification of air basin pollution sources based on the analysis of well-known methodological approaches with the subsequent improvement of calculation methods for substantiating the spatial distribution of residential areas, industrial areas, motorways, recreational areas, effective sanitary protection zones taking into account aerodynamics for the removal of polluted air outside the city territory [4]. Moreover, the sources of air pollution in urban areas are classified according to the following main features. Thus, by origin, the sources are divided into $[5,6]$ :

1. natural, arising as a result of various natural phenomena and processes, which primarily include volcanic eruptions, forest and steppe fires, dust storms. Examples of pollutants emitted by such sources are: dust of vegetable, animal and volcanic origin, dust resulting from soil erosion, particles of sea salt, fog, fumes and gases from forest fires, various products of plant, animal and microbiological origin;

2. anthropogenic (artificial) arising in the process of human activity. In turn, they are divided into transport (motor transport, railway transport, river and sea transport, air transport), production (various technological processes), household (boiler houses, enterprises for the processing of household waste).

In this group, transport sources occupy a leading position [7]. Moreover, in the general structure of transport sources, the maximum share of atmospheric emissions is accounted for by motor transport, which significantly exceeds the share of emissions from rail transport, represented mainly by diesel locomotives. In addition, over the past few years, there has been a tendency to increase traffic flows on the highways of large cities, resulting in an intensive increase in emissions of pollutants from exhaust gases of internal combustion engines. The priority pollutant is carbon monoxide, which accounts for $64 \%$ of the total emissions. Along with this, nitrogen and sulfur oxides, hydrocarbons, benz(a)pyrene and other substances are emitted into the atmospheric air of urban buildings. The greatest contribution to the pollution of the atmosphere is made by gasoline-powered cars, to a lesser extent by diesel-powered cars, and gas-fired vehicles make a minimal contribution.

Further, in descending order of the share of emissions are air, sea and river transport.

In aviation, the use of gas turbine propulsion systems results in the emission of toxic components such as carbon monoxide, nitrogen oxides, hydrocarbons, soot, aldehydes and others. It should be noted that the total emissions of pollutants (carbon monoxide, hydrocarbons, nitrogen oxides, aerosols) by aircraft engines are relatively small, however, they accumulate sufficiently in the vicinity of the airports and make a significant contribution to environmental pollution.

Waterborne vehicles are a significant sources of air pollution with freons, heavy metals, soot, and dust. 
Thus, we can conclude that transport sources of pollution of urban areas are the most powerful compared to industrial and domestic.

The second place in the contribution to the pollution of the air basin of large cities in the group of anthropogenic sources of emissions is occupied by production sources, which are very diverse in terms of industry and the list of pollutants emitted.

Long-term studies have established that in this group the leading place in the contribution to the pollution of the air basin of large cities is occupied by heat and power enterprises, including boiler houses of centralized heat supply systems. Depending on the type of fuel burned (gas, fuel oil, diesel, wood, coke, coal, peat), such pollutants as sulfur dioxide, nitrogen oxides, volatile organic compounds, aromatic hydrocarbons, heavy metals, and solid metals, emitted into the atmosphere particles of various chemical composition and sizes.

Next, in the general structure of production sources, a significant share of atmospheric emissions is accounted for by the metallurgical industry, which is mainly characterized by gaseous emissions with intense heat. The metallurgical industry is followed by the construction industry, which is mainly characterized by emissions of solid (dust) particles.

According to the aerodynamic parameters and the nature of the orientation (organization) of pollutant emissions, the sources are divided into:

1. organized, which are characterized by compactness, strict directivity of the velocity vector of the pollution plume through specially constructed channel structures (gas ducts, air ducts, chimneys, etc.). As a rule, such sources are characterized by a significant height from the earth's surface, as well as significant concentrations and volumes of pollutants emitted. In turn, organized sources are divided into technological, providing regulated parameters of technological processes, and ventilation related to the operation of general exchange and local ventilation systems;

2. unorganized, which are characterized by a relatively large emission area, a sufficiently wide range of its velocity in freely propagating atmospheric air flows without passing through any channels. Such sources is open storage of various types of fuel, bulk materials, various types of waste, etc. The emission power of such sources depends on weather and climate conditions in the area of the source location and, above all, on the speed of the wind load.

According to the spatial position and possible mobility, the sources are divided into the following types $[9,10]$ :

1. stationary, which do not change their location in space and which include sources with organized or unorganized release of a polluting substance (gas ducts, air ducts, chimneys, open storage facilities for various types of fuel, bulk materials, various types of waste, etc.), functioning permanently or temporarily within the boundaries of the considered area of the territory of the investigated object;

2. mobile, which change in time their location in space and which can also include sources with organized or unorganized release of a pollutant (all types of transport: road, rail, air, sea, river, as well as various moving conveying devices: conveyors, conveyor lines, elevators, etc.). It is mobile sources with positions of negative impact on the air basin of large cities that deserve special attention.

Based on the analysis of work of many authors $[5,6,10]$ and the results of our long-term studies of the operation of various types of sources of emissions of pollutants into the atmosphere [4,7], we propose a systematization of these sources in terms of size. At the same time, we recommended subdividing all emission sources into:

1. point, the dimensions of which in the plan along any of the coordinate axes do not exceed $1 \mathrm{~m}$ (exhaust sections of pipes, roof fans, chimneys and others);

2. linear, the dimensions of which in the plan along any of the coordinate axes exceed $1 \mathrm{~m}$, and on all other axes do not exceed $1 \mathrm{~m}$ and which are characterized by a linear type of 
placement in space (aeration lamps, conveying devices: conveyors, conveyor lines, channels etc.);

3. areal (planar), the dimensions of which in the plan along all coordinate axes exceed $1 \mathrm{~m}$ and which are characterized by dispersed emission characteristics. Such sources can be either single (separate) or group (multiple, located close to each other) and, as a rule, are unorganized (open storage facilities for various types of fuel, bulk materials, various types of waste, etc.)

Based on the analysis of the work of many authors [6,7] and the results of our multiyear studies of the operation of various types of sources of pollutant emissions into the atmosphere [10], we also suggest the systematization of these sources according to the height of the spread of the emission plume, taking into account the height of the mouth of the source of pollutant emission substances above ground level. At the same time, we recommended subdividing all emission sources into:

1. high, the emission plume of which is distributed in such a way (at such a height) that it absolutely does not fall into the circulation zone (aerodynamic shadow zone) of nearby objects, buildings and structures. High sources include, for example, chimneys of state district power plants, thermal power plants, boiler houses and other heat power plants with a height of $120 \mathrm{~m}$ and above, the plume of which at such a height above the earth's surface and at any wind load (even with calm) is guaranteed not to fall into circulation zone of nearby objects, buildings and structures;

2. low, the emission plume of which is distributed in such a way (at such a height) that it at least partially enters the circulation zone (aerodynamic shadow zone) of nearby objects, buildings and structures. Low sources include, for example, openly located processing equipment, open storage facilities for various types of fuel, bulk materials, various types of waste, etc.

In addition, exhaust pipes of all types of automobile and railway vehicles running on gasoline, diesel or gas fuel are low sources. At the same time, the maximum emission of pollutants is observed during the operation of internal combustion engines in open parking lots of vehicles during their start-up and warm-up, idling, maneuvering on the territory of parking lots or in production areas, as well as loading and unloading of vehicles.

It is known [11] that sources of emission of pollutants are also subdivided according to the temperature of the gas-air mixture leaving the atmosphere as follows:

1. heated, characteristic for emission sources from technological equipment that implements technological processes at temperatures exceeding the ambient temperature by 20 $30^{\circ} \mathrm{C}$. So, emissions of metallurgical enterprises that are formed during the primary processing of ore in blast furnaces, electric arc furnaces, converters, and in the process of metal smelting, which are characterized by a temperature reaching $120-140^{\circ} \mathrm{C}$ when released into the atmosphere, can be considered heated. The emissions of chimneys of enterprises of the fuel and energy complex, resulting from the combustion of fuelhaveabout the same temperature;

2. cold, typical for emission sources from technological equipment that implements technological processes at temperatures very close in value to the ambient temperature (differing by about $1-5^{\circ} \mathrm{C}$ ). So, cold emissions can be considered as a rule from unorganized sources represented by open storages of various types of fuel, bulk materials, various types of waste, etc., as well as emissions from ventilation systems from various technological equipment and from the internal volume of premises in the summer.

In accordance with the generally recognized classification $[5,6,10]$, sources of pollutant emissions are also subdivided according to the mode of action as follows:

1. continuous operation, which are characterized by uniform, not changing in time basic parameters of the plume of emission of pollutants (mass emission, average speed). Such sources include, for example, sources of emissions from technological equipment that 
implements technological processes at enterprises of various industries, as well as chimneys of state district power plants, thermal power plants, boiler houses and other thermal power plants operating in continuous operation [12];

2. periodic operation, which are characterized by non-uniform, time-varying basic parameters of the plume of pollutant emissions (mass emission, average speed). Such sources include, in particular, the sources listed above, but operating in a variable mode of operation;

3. peak, which are characterized by a short (within 20 minutes) emission of pollutants, which has significant power. Such emissions occur in the event of technological accidents, or during a single peak (for a short period of time) of burning of combustible technological raw materials of various types of production, which in some cases is provided for by the technological regulation and is caused by separate (specific) stages of certain technological processes.

\section{Results and discussion section}

Based on our analysis and studies of the classification features of sources of various types of pollutants emitted into the air basin of the territories of large cities, a comprehensive classification scheme has been built (figure).

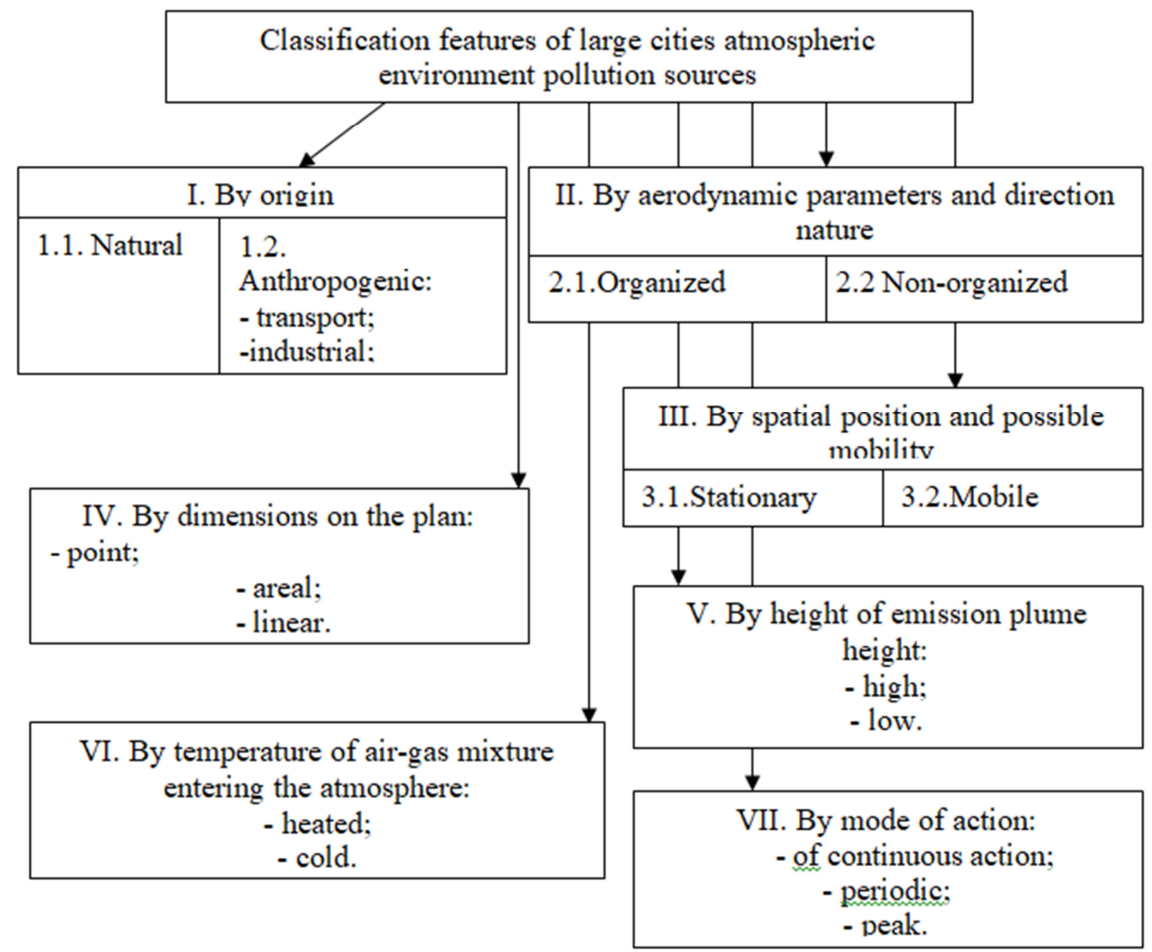

Fig.1. Classification features of large cities atmospheric environment pollution sources.

\section{Conclusions}


Thus, the presented systematization of sources allows us to propose a comprehensive classification scheme that allows practically any source of pollutant emissions into the air basin of the territories of large cities to be comprehensively characterized in such a way that its identified parameters and behavioral features will provide the opportunity to choose the best ecological efficiency and energy efficiency of the means of suppressing the mentioned emissions and ensuring environmental safety of the urban environment.

\section{References}

1. V.I. Bespalov, O.S. Gurova, O.N. Paramonova, Publ. by Rost. State Construction Univ., $176 \mathrm{p}(2015)$

2. B.T. Badaguev, Ecological safety of the enterprise: Orders, acts, instructions, magazines, regulations, plans, 568 (2016)

3. O.S. Gurova, Naukovedenie, 5 (2013) URL: http: //naukovedenie.ru/sbornik6/4.pdf

4. N.M. Larionov, Industrial ecology (2016)

5. V.V. Reshetov, V.V. Sevastyanov, A. M. Grisenko, Environmental safety in rail transport. "IPK"Costa" (2015)

6. V.I. Bespalov, O.S. Gurova, L.N. Alekseenko, MATEC Web of Conferences 226, 04015 (2018) DTS-2018//https://doi.org/10.1051/matecconf/20182204015

7. V.I. Bespalov, O.S. Gurova, N.S. Samarskaya, Scie. Revi. Mag., 9(3), 710-714 (2014)

8. V.I. Bespalov, O.S. Gurova, N.S. Samarskaya, Biosciences, Biotechn. Rese.Asia, 12 (2), 1587-1596 (2015)

9. K.F. Saevich, Ecology of the urban environment (2014)

10. E.P. Lysova, Construction - 2013, 122-124 (2013)

11. V.I. Bespalov, E.P. Lysova, Magaz. "Scien. Revi.", 7(3), 914-917 (2014)

12. V.I. Bespalov, O.S. Gurova, S.V. Meshcheryakov, E.P. Lysova, Proc. Appa. Redu. Ai Pollu., part 2, 172 (2015) 